\title{
'What is (mental) disease?': an open letter to Christopher Boorse
}

K W M Fulford University of Warwick and University of Oxford

\begin{abstract}
This "open letter" to Christopher Boorse is a response to his influential naturalist (value-excluding) analysis of disease from the perspective of linguistic-analytic value theory. The key linguistic-analytic point against Boorse (and other naturalists) is that, although defining disease value free, he (and they) continue to use the term with clear evaluative connotations. $A$ descriptivist (value-entailing) analysis of disease would allow value-free definition consistently with value-laden use: but descriptivism fails when applied to mental disorder because it depends on shared values whereas the values relevant to mental disorders are highly diverse. A part-function analysis, similarly, although initially persuasive for physical disorders, fails with the psychotic mental disorders because these, characteristically, involve disturbances of the rationality of the person as a whole. The difficulties encountered in applying naturalism to mental disorders point, linguistic-analytically, to the possibility that there is, after all, an evaluative element of meaning, deeply hidden but still logically operative, in the concept of disease.

(Fournal of Medical Ethics 2001;27:80-85)
\end{abstract}

Keywords: Mental illness; mental disorder; concept of disease; value theory; medical model; psychosis; function; action

There is a surprise at the heart of Christopher Boorse's recent extensive restatement of his influential theory of disease in the collection of papers, edited by J M Humber and R F Almeder, What is Disease? ? $^{1}$

The surprise is this. Boorse's work started from, ${ }^{2}$ and originally was concerned substantively with, ${ }^{3}$ the concept of mental disorder ${ }^{4}$; in later papers he has returned to this topic ${ }^{5}$; yet in What is Disease?, a full twenty years on, mental disorder has been bracketed out. The collection includes a number of important contributions to the literature on the health concepts. Among these, there are chapters touching on mental disorder: Stan van Hooft's Disease and subjectivity, for example ${ }^{6}$; and Michae Ruse's Disease concepts and sexual orientation. But none deal with mental disorder as such. And in Boorse's own contribution, his 134-page A rebuttal on health, mental disorder receives a mere (and un-indexed) two pages, between pages 60 and $62 .{ }^{8}$
At first glance, it may seem that there is no surprise here. What is Disease?, after all, in neglecting mental disorder, is following fashion. It is physical disorder, not mental disorder, that has been the main focus both of critiques of Boorse's theory and of philosophical work on the health concepts generally; and Boorse, in his "Rebuttal", was replying in kind. This wider neglect of mental disorder, however, is no less surprising than its neglect in What is Disease? For it is with mental disorder, not physical disorder, that the most acute conceptual difficulties in clinical work and research in medicine arise. This is why Boorse originally started from mental disorder.

In this open letter I argue, from the perspective of linguistic-analytic value theory, that mental disorder, far from being bracketed out of the literature on the health concepts, should be made centre stage. I develop this idea mainly by way of a response to Boorse's generous treatment of the linguistic-analytic critique of his theory in chapter 3 of my Moral Theory and Medical Practice. ${ }^{9}$ I make three points: 1) that Boorse's naturalist (valueexcluding) medical model of disease leads him into inconsistencies; 2) that the only self-consistent form of the medical model, a descriptivist (valueentailing) medical model, fails when applied to the problems raised by mental disorder; and 3) that the "part function" account of dysfunction on which Boorse relies for his naturalist (value-excluding) medical model, fails when applied to the problems raised by the central kind of mental disorder, psychosis.

\section{1) Naturalist (value-excluding) medical} models

In a series of papers starting in the $1970 \mathrm{~s}^{23} 5^{10-12}$, and in his "Rebuttal", 8 Boorse has developed a detailed naturalistic account of the concept of disease. His aim in this, like the aim of other naturalists (such as Jerome Wakefield, for example ${ }^{13}$ ), has been to show that, while medical practice may be value-laden, medical theory is at heart value free, and, hence, scientific.

Boorse's aim, of showing that medical theory is value free, connects directly with his starting point, namely mental disorder. The "problem" with mental disorder, as Boorse defined it, and as many others in the wider psychiatry versus anti-psychiatry debate at the time had argued ( $\operatorname{see}^{918}$ for review), is that it is at risk of taking over the territory of morals. "Whether the topic is criminal responsibility, 
sexual deviance, feminism, or a host of others ..." Boorse argued, there is a "growing preference for medicine over morals ....". ${ }^{14}$ The solution, then, to this "psychiatric turn", ${ }^{14}$ is to restrict the scope of psychiatry to its properly medical role by sharpening up its scientific terms of reference.

Boorse recognised, before anyone else, that one way to sharpen up the science in psychiatry is to distinguish between medical practice (which is overtly value laden) and medical theory (which is ostensibly value free and, hence, on this view, scientific). He did this by a stipulative (and entirely reasonable) distinction between the concepts of disease and illness. Disease, he suggested, is a value-free scientific term, at least as used in medical theory. A disease is a "deviation" from the norms of functioning typical for the species of which the organism in question is a member. ${ }^{15}$ Disease, again, is "mainly due to environmental causes".${ }^{15}$ Illness, on the other hand, is connected with the practica applications of medical theory-an illness is a disease which is "serious enough to be incapacitating". ${ }^{16}$ Illness, therefore, in being (among other things) "undesirable for its bearer", ${ }^{16}$ is value laden while disease is value free.

There is much to be said for and against both Boorse's model (see for example, besides Humber and Almeder, ${ }^{1}$ Nordenfelt ${ }^{17}$ ) and the wider category of "medical" models to which it belongs (for review, $\left.\mathrm{see}^{18}\right)$. As a value-excluding model it is closely related to a large literature in what is sometimes called the philosophy of biology on whether function terms (including the concept of disturbed functioning) can be defined value free. Boorse draws explicitly on this literature (for example ${ }^{11}$; also $^{12}$ ) and I return to this in section 3 of this paper, below. Also relevant is the similarly large literature on whether science itself is value free (see, for example, Hesse, ${ }^{19}$ for a balanced discussion on this). Equally important, though less well recognised, is the other side of the fact-value coin, work in theoretical ethics on whether values can be defined by reference to facts alone: the "is-ought debate", as it is sometimes called, is a rich resource of at least 200 years of philosophical work, stretching back to David Hume and beyond, which has been left largely untapped in current debates about concepts of disorder (see Warnock, ${ }^{20}$ for a clear introduction).

The specific point against Boorse, though, from the perspective of linguistic-analytic philosophy, and the key point that I make in chapter 3 of my Moral Theory and Medical Practice, ${ }^{9}$ is that he is inconsistent in his use of language. He is careful to define disease in terms that are value free. But he then goes on to use disease with clear evaluative connotations. For example, having defined disease value free as a "deviation" from functional norms, three lines later disease has become the value-laden "deficiencies in functional efficiency", ${ }^{15}$ (emphases added); similarly, Boorse's value-free addendum to his definition, that disease is mainly due to "environmental causes" becomes, again within a few lines, the value-laden "hostile environment", ${ }^{15}$ (emphasis added).

From the perspective of linguistic-analytic philosophy, these, and other similar shifts from value-free definitions to value-laden uses of language (described fully in my chapter $3^{9}$ ), are highly significant. The key methodological insight of linguistic-analytic philosophy, as described most explicitly by the Oxford philosopher, J L Austin, ${ }^{21}$ is that the words we use may act as a kind of analytical probe to, or microscope on, meanings. The basis of this is the observation that people are in general better at using (particularly high-level) concepts than at defining them (I use the concept of "time" all the time but cannot define it). Hence our use of such concepts, ie the words we use for real, may be a surer guide to their meanings than attempts to define them. Hence Boorse's use of "disease" with evaluative connotations may signal that, his valuefree definition of disease notwithstanding, there is an essential evaluative element in the meaning of the term.

From Boorse's perspective, by contrast, his slips from value-free definition to value-laden usage are a small matter, incidental to the main event, and readily fixed (if fixing is needed) either by direct substitution (replacing the offending value-terms with value-free descriptive terms) or by drawing on deeper theory (the analysis of biological-function terms underpinning his analysis of disease). I return to the second option, reference to deeper theory, in section 3 below. The first option, direct substitution, brings us to descriptivism.

\section{2) Descriptivist (value-entailing) medical models}

Boorse is a naturalist not a descriptivist on disease: as he puts it in his "Rebuttal", he "has never drawn a descriptivist breath". ${ }^{22} \mathrm{He}$ starts from the value-excluding position that disease, and with it medical theory, is value free. Yet the debate in my chapter $3,{ }^{9}$ he suggests, "creates the impression that the descriptivist is my (Boorse's) defender..." 22

I resist this last suggestion. My chapter 3 takes the form of a debate between a descriptivist and a non-descriptivist philosopher, both working within the linguistic-analytic tradition, and both of whom take Boorse's slips from value-free definition to value-laden use to be significant. Moreover, far from defending Boorse's naturalist position, they share the view that descriptivism offers him, and naturalist medical models in general, a way out.

We need to be careful here. There are (at least) three different senses in which value terms might be taken to be replaceable by descriptive terms: 1) by substituting descriptions of values for values; 2 ) by the use of equivocal terms; and 3) by defining the value terms in question by reference to the descriptive criteria for the value judgments they express. This last sense, sense 3, is descriptivism, as this term is used in recent philosophical value theory (for example by another Oxford philosopher, 
G J Warnock ${ }^{23}$ ). And it is only in sense 3, that substituting descriptive for value terms offers the medical model a way out. ${ }^{2425}$

Thus, where naturalism excludes values, the descriptivist position is that, under certain circumstances, a given set of facts implies a given value judgment (strictly implies, ie implies by definition, as "bitch" implies "female dog"). Descriptivism argues that in certain circumstances the evaluative meaning carried by a word or phrase may be redefined in terms of the descriptive criteria for the value judgment the word or phrase in question is used to express.

The distinction between (value-excluding) naturalism and (value-entailing) descriptivism is well illustrated by Boorse's example of "better by $5 / 8$ " used of the share price of IBM. ${ }^{26}$ This is just the kind of case descriptivist moral philosophers, such as Warnock, ${ }^{23}$ have in mind. "Better", as Boorse notes, is an "evaluative term"; but in this context it means "higher"; it describes the share price of IBM as having gone up by 5/8. So, the (naturalist) Boorse says, drawing a direct parallel with his shifts from value-free definition to value-laden use of disease (noted in section 1), the use of "better" in this context is no more than "harmless ... rhetoric". The (descriptivist) Warnock, by contrast, says: "higher by $5 / 8$ " is indeed descriptive; but in this context the description "higher by $5 / 8$ " is the descriptive criterion for the value judgment expressed by "better by $5 / 8$ ". In this context, the evaluative "better by $5 / 8$ " can indeed be translated without loss of meaning into "higher by $5 / 8$ "; this is because the descriptive criteria for "better" used of share prices is fixed by conventional definition; but by the same (definitional) token, describing the price of IBM as "higher by $5 / 8$ " implies the evaluative "better by $5 / 8$ ". Hence value-free definition of a value term in this context is consistent with value-laden use. Contrast this, finally, with "higher by $5 / 8$ " used by, say, a carpenter. This too is descriptive; but it is descriptive only of a change in height; and it thus does not entail a value judgment (though of course it may still carry evaluative meaning contingently rather than by definition)

Descriptivism, therefore, allows us to have our cake and to eat it with regard to facts and values. Its redefinition of values in terms of facts, applied to disease theory, would thus give Boorse what he requires, a value-free science of health. But the values implied by those facts would allow the term "disease" still to be used, as Boorse uses it, with evaluative connotations. A descriptivist medical model is therefore, in this respect at least, more self-consistent than Boorse's naturalist model; and it is in this sense that, as I said at the start of this section, it offers naturalists a way out. ${ }^{27}$

So where's the rub? For, in my chapter $3,{ }^{9}$ it is the non-descriptivist, not the descriptivist, who gets the last word. The rub is that in the case of mental disorder, the key condition required by descriptivists, for their redefinition of values in terms of facts, is not satisfied. The relevant condition is that the values in question are largely shared. There is no problem, then, for disease concepts in acute physical medicine: a heart attack, in itself, and for the person concerned, is a bad condition for anyone. ${ }^{28}$ Here our values are shared. But in psychiatry, as I show in chapter 5 of Moral Theory and Medical Practice, ${ }^{29}$ we are concerned, typically, with desires, beliefs, emotions, motivations, and so forth, areas of experience and behaviour in which human values are, characteristically and legitimately, diverse. In psychiatry, then, our values are not shared. Hence, while the descriptivist redefinition of values in terms of facts might be available for disease concepts in acute physical medicine, it is not available in psychiatry.

Boorse, then, to the extent that he is concerned, ultimately, with mental disorder, is right to insist that he is a naturalist, not a descriptivist, on disease. In my chapter $3,{ }^{9}$ the non-descriptivist, largely following yet another Oxford philosopher, R M Hare, (see, for example, ${ }^{30}$ and $^{31}$ ), adduces general arguments against descriptivism. This is why the non-descriptivist, rather than the descriptivist, gets the last word. But the point is that descriptivism, even if available in principle to Boorse, would not generate a theory of disease which is fit for his (original) purpose. For Boorse's original target, remember, in seeking to develop a value-free science of health, was mental disorder. But descriptivism, because human values are diverse in the areas of experience and behaviour with which psychiatry is concerned, is not applicable to mental disorder. Hence Boorse is right to be a naturalist not a descriptivist on disease. But his own use of the concept (with evaluative connotations) shows that a naturalist (value-excluding) definition of disease fails to capture the full (fact + value) meaning of the term.

\section{3) Part-function medical models}

Naturalism has another string to its bow, however, in the concept of function. In his "Rebuttal", Boorse $^{32}$ rightly accuses me of neglecting, in my chapter $3,{ }^{9}$ his detailed work on this concept (for example, in $^{11}$ and $^{12}$ ). Like other naturalists, he takes the concept of function to offer a deeper level of theory underpinning analyses of the health concepts; and he argues that reference to this underlying theory shows his use of value terms in respect of disease to be, analytically speaking, epiphenomenal (not his term). I do, however, take up the concept of function in my chapter $6 .^{33}$ In that chapter, although not referring directly to Boorse's work, I explore the issue which is central to any naturalist account of function, namely whether function (hence dysfunction, and hence disease) can be defined value free.

My focus in Moral Theory and Medical Practice, it is true, is different from Boorse's; my focus (in my chapters 6 and 7$)^{34}$ is the particular kind of value expressed by the medical concepts (illness being different from ugliness, for example, and mad from bad). I trace "medical" value from its overt expression in illness (and even more overt expression in disorder) through disease to dysfunction and from 
there to function. ${ }^{35}$ Boorse, like other naturalists, runs the argument the other way. Naturalists, as I have shown in detail elsewhere, ${ }^{35}$ vary in where they take the evaluative element in the medical concepts to come in: between function and dysfunction, or between dysfunction and disease, or between disease and illness (this is Boorse's line, in $1975^{2}$ ), or between dysfunction and disorder. But the idea linking all these naturalist approaches is that function is a biological concept which grounds medicine in value-free science.

\section{Teleology}

The trick, then, for the naturalist, is to define function value free. This is not as straightforward as it might seem. For while it is true that function is a term of art in biology (which is a science), it is a teleological rather than (purely) causal term; and teleology (as I argue in my chapter $6^{33}$ ) can be connected conceptually through purposes and intentions to values. This is why, paraphrasing Boorse's example ${ }^{36}$ we can and do speak literally of "good for rats" but only (and if at all) metaphorically of "good for clouds". As the Warwick philosopher Tim Thornton, has pointed out, ${ }^{37}{ }^{38}$ and as I agree, ${ }^{33}$ the connection between teleology and values should not be taken for granted. All the same, "value-free" has generally been taken by naturalists to require "teleology-free" ${ }^{35}$ Defining function value free thus depends, in the work of most naturalists, on reducing teleological explanation to causal explanation.

Boorse in effect takes a more subtle approach. $\mathrm{He}$ retains the teleological element of meaning in the concept of goal ${ }^{11}{ }_{12}$ and defines function causally as "a standard causal contribution to a goal actually pursued by the organism" ${ }^{39} \mathrm{He}$ connects this definition with reduced survival and reproduction as criteria of dysfunction, since, as evolutionary theory emphasises, survival and reproduction are goals actually pursued by organisms. A particular strength of this definition is that, as Boorse notes against my chapter 3 example of driving racing cars (which is associated with reduced survival but is not a disease ${ }^{40}$ ), it limits the relevant causal contributions to bodily (and mental) parts. This is a particular strength of the definition linguistic-analytically, because function is indeed used, in respect of organisms at least, of their parts. The term does have a (non-metaphorical) use in respect of whole organisms; but this is only when the organism in question is functioning as part of a larger group (an "alpha male", for example, or a nurse, both have functions in this sense (see generally, 9, chapter $6^{33}$ ).

There are, however, two difficulties with this account from the perspective of linguistic-analytic philosophy, one general, the other specific. The general difficulty is with the concept of goal. The point is an extension of that made above against naturalism on disease. The concept of a "goal", being a teleological concept, does allow us to speak of good and bad functioning by reference to whether or not the goal in question is attained. But this is because goal itself, to the extent that it is a teleological concept, carries an evaluative element of meaning. A goal is not, merely, something which is hit or missed, as, say, a comet merely hits or misses a planet: a goal is aimed at or targeted; it may (according to the teleological resources of the organism or part-organism in question) be desired, needed, wished for, intended, etc; a goal is something which (in itself) it is good to hit and bad to miss. ${ }^{41}$

A descriptivist (as opposed to a naturalist) account of "goal", and hence of function and dysfunction, like the descriptivist account of disease discussed in section 2 above, does allow (in principle) value-free redefinitions of all these terms consistently with their continued use with evaluative connotations. In the case of function and dysfunction, moreover, and indeed of goal (as used in this biological context), the precondition for the descriptivist redefinition is satisfied: the criteria for the value judgments implicit in function are indeed relatively fixed, contingently in the case of biological functional objects (as Boorse notes, a wellfunctioning heart, for example, contributes to any goal of an organism), analytically (ie by definition) in the case of artificial functional objects (ultimately, by the intentions of their designers - see my chapter 6 of Moral Theory and Medical Practice ${ }^{33}$ ). The naturalist, however, is committed not only to defining but also to using these terms value free. And this, the language of naturalists themselves suggests, they cannot do. ${ }^{42}$

The specific difficulty with Boorse's account of function is that its particular strength, linguisticanalytically, turns out to be its Achilles' heel when he turns his account back to mental disorder. The "part function", which his "standard causal contribution" requires, is persuasive in respect of bodily diseases, which, typically, involve disturbances of bodily parts and systems (such as livers, immune systems, etc). It is also persuasive in respect of some mental disorders (such as the neuroses). But as Boorse himself notes, mental disorders may involve, not mental parts and systems, but the person as a whole. Boorse cites personality (or "character") disorder"; but the point is made even more strongly by the psychotic disorders, such as schizophrenia. Boorse has argued that such disorders fit his part-function analysis rather well (for example ${ }^{43}$; and by implication in his "Rebuttal" delusion, which is the central feature of such disorders, has steadfastly resisted analysis in partfunction (part-cognitive-function) terms (for a recent review, se ${ }^{45}$ ). And as I showed in chapter 10 of Moral Theory and Medical Practice, ${ }^{46}$ the psychopathology of delusions themselves points to the underlying disorder of rationality involving, not some disturbance of part (cognitive) functioning, but rather of practical reasoning, ie, that form of reasoning that is characteristic of agents as a whole.

\section{Mis-match}

This mis-match, between part-functioning analyses of disease and the psychoses, was foreshadowed by an earlier advocate of the "part-function" theory of 
mental disorder, no less a figure than one of the founders of scientific psychiatry, Sir Aubrey Lewis. ${ }^{47}$ It is important to recognise how deep the difficulty goes. The functional psychotic disorders are not peripheral but central in our psychopathology. As Thomas Szasz, the arch antipsychiatrist, put it, schizophrenia is the "sacred symbol of psychiatry" ${ }^{48}$ If schizophrenia is not a mental disease (or at any rate a severe mental disorder), then nothing is a mental disease. A failure, therefore, on psychosis, of a theory of disease the aim of which, like Boorse's, is to resolve the conceptual problems associated with mental disorder, is a central, not peripheral, failure of theory.

Where one goes from there is a matter of continuing debate. For some, it means searching for a different function-based account of disorder, one which will accommodate rather than conflict with the features of psychosis. The work of the British philosopher Christopher Megone on Aristotle's analysis of function (applicable to persons as well as parts) may be fruitful in this respect. ${ }^{49}$ My own approach, set out in chapters 7 to 10 of Moral Theory and Medical Practice, ${ }^{50}$ is to enlarge the conceptual resources of medicine to include action, the "doing" word associated with agents (paradigmatically, persons), as well as function (the "doing" word associated with parts). I do not have space to set out the details of this approach here. But a key result of enlarging the conceptual resources available to us in this way, is to produce a theory which accommodates the psychotic disorders.

\section{Conclusions: a plea for mental disorder}

In this open letter to Christopher Boorse I have argued that his naturalist theory of disease fails to accommodate the mental disorders which were the original target of his work. Boorse was among the first to demonstrate that fact and value, as logical elements, are woven together into the conceptual structure of medicine. His theory has thus been, and remains, important and innovative. As a naturalist theory of disease, though, it fails (from the perspective of linguistic-analytic philosophy) through inconsistency, through his repeated slips from value-free definition to value-laden use of the concept. A descriptivist theory of disease, in redefining values in terms of facts, rather than excluding them, allows value-free definition to be combined with value-laden use; but this fails when applied to mental disorders because descriptivism depends on shared values, whereas, in the case of mental disorders, the relevant values are highly diverse. Part-functioning naturalist theories of disease, similarly, are initially persuasive in respect of physical disorders and some mental disorders; but they fail when applied to the paradigm mental disorders, the psychoses, to the extent that these involve disturbances of the person as a whole.

This result, the failure of value-free theories of disease when applied to mental disorders, could be taken in different ways. The antipsychiatrists, such as Thomas Szasz ${ }^{51}{ }^{52}$ will take it as showing, as they have argued all along, that mental disorders are not, properly, part of medicine. Propsychiatrists, those who believe that mental disorders (or some mental disorders at least) are part of medicine, will take it as showing the need for an improved "medical" model, perhaps based on a different analysis of function (as in Megone's ${ }^{49}$ and Thornton's ${ }^{37}$ work noted above).

Linguistic-analytic philosophy suggests a third way, namely, that instead of taking the failure of value-free theories of disease when applied to mental disorders as a conclusion against mental disorders, we should take it rather as a conclusion against value-free theories of disease. Again, I do not have not space to go into this in detail $\left(\mathrm{see}^{53}\right.$ and $\left.{ }^{54}\right)$. But the point is that, rather as diabetes led to the discovery of insulin, so difficulties in the use of a concept, if they are taken seriously, may provide insights into the meaning of that concept. J L Austin made this point in his foundational linguisticanalytic paper, A plea for excuses. ${ }^{21}$ We are just $s o$ good at using (high level) concepts (such as disease), he argued, that it is sometimes only when we run into difficulties that we are able to break through the "blinding veil of ease and obviousness" by which their full meanings are normally hidden from us. ${ }^{55}$

Boorse takes it as obvious that biology in general, and the concept of (biological) function in particular, are both value free. Normativism about biology, he says, is "implausible" "56 ; so much so that it is too "high (a) price" to pay for normativism about health ${ }^{57}$ Well, beware the obvious, Austin would have said! To the contrary, he might have added, the difficulties we run into when we try to apply non-normative theories of disease to mental disorder, point (linguistic-analytically) to the possibility that the health concepts in general, theoretical as well as practical, are, despite appearances, normative rather than naturalist in nature.

Mental disorder, then, could be the key to breaking through a "blinding veil" of naturalism by which the evaluative element in the meanings of the (theoretical) health concepts is hidden. This is why, as I said at the start of this article, mental disorder, instead of being bracketed out, as in Boorse's theory and in the wider literature on concepts of disorder, should be brought to centre stage. No theory of disorder if not a theory of mental disorder; no theory of disease if not a theory of mental disease.

\section{Acknowledgements}

I am very grateful to Christopher Boorse and to Tony Hope for their detailed comments on earlier drafts of this paper.

Bill (KWM) Fulford, Dphil, FRCP, FRCPsych, is Professor of Philosophy and Mental Health, University of Warwick, Honorary Consultant Psychiatrist, University of Oxford and Editor of Philosophy, Psychiatry and Psychology. 


\section{References and notes}

1 Humber JM, Almeder RF, eds. What is disease? Totowa, New Jersey: Humana Press, 1997.

2 Boorse C. On the distinction between disease and illness. Philosophy and Public Affairs 1975;5:49-68.

3 Boorse C. What a theory of mental health should be. Fournal of Theory Social Behaviour 1976;6:61-84.

4 I use "disorder" in this article as a generic term covering disease, illness, dysfunction, etc. The differences between these terms, as Boorse was among the first to show, are of course of central importance in philosophical work on the health concepts.

5 Boorse C. Concepts of health. In: Van de Veer D, Regan T, eds Health care ethics: an introduction. Philadelphia: Temple University Press, 1987: 359-93.

6 Van Hooft S. Disease and subjectivity. See reference 1: ch 7.

7 Ruse M. Defining disease: the question of sexual orientation. See reference 1: ch 2 .

8 Boorse C. A rebuttal on health. See reference 1: ch 1 .

9 Fulford KWM. Moral theory and medical practice. Cambridge: Cambridge University Press, 1989: ch 3 (reprinted 1995 and 1999; 2nd ed forthcoming).

10 Boorse C. What a theory of mental health should be. Fournal of Theory Social Behaviour 1976; 6:61-84

11 Boorse C. Wright on functions. Philosophy Review 1976;85:7086.

12 Boorse C. Health as a theoretical concept. Philosophy of Science 977;44:542-73.

13 Wakefield JC. Aristotle as sociobiologist: the "function of human being" argument, black box essentialism, and the concept of mental disorder. Philosophy, Psychiatry, and Psychology 2000;7,1:17-44.

14 See reference 2: 49 .

15 See reference 2: 59

16 See reference $2: 61$

17 Nordenfelt L. Health, science and ordinary language. Amsterdam: Rodopi (forthcoming). Note that in his "rebuttal" Boorse has developed his theory in certain respects: he no longer employs the disease/illness distinction; and he has dropped the "environmental" subclause. But the core feature of his model, a naturalist (value-excluding) definition of disease as the basis of value-free scientific medical theory, remains the basis

18 Fulford KWM. Mental illness. In: Chadwick R, ed. Encylopaedia of applied ethics. San Diego: Academic Press, 1998.

19 Hesse M. Revolutions and reconstructions in the philosophy of science. Brighton: The Harvester Press, 1980.

20 Warnock GJ. Contemporary moral philosophy. London and Basingstoke: The Macmillan Press: 1967.

21 Austin JL. A plea for excuses. Proceedings of the Aristotelian Society 1956-7;57:1-30. Reprinted in White AR, ed. The philosoph of action. Oxford: Oxford University Press, 1968.

22 See reference 8: 22 .

23 Warnock GJ. The object of morality. London: Methuen, 1971.

24 I have considered the other two senses in detail elsewhere, sense 1 in reference 35: Teleology without tears and sense 2 in reference 25: Nine variations and a coda.

25 Fulford KWM. Nine variations and a coda on the theme of an evolutionary definition of dysfunction. Fournal of Abnormal Psyevolutionary definition of
chology 1999;108:412-20.

26 See reference 8: 104 , note 14

27 I have developed the idea of a descriptivist medical model in The concept of disease. Bloch S, Chodoff P, eds. Psychiatric thics [2nd ed]. Oxford: Oxford University Press: ch 6. This has ome interesting possibilities also for nosology, building particularly on an account of conventional definition developed by another Oxford philosopher, J O Urmson. Urmson JO. On grading. Mind 1950;59:145-69.

28 "in itself", note: a heart attack, although in itself a bad condition for anyone may, contingently, go on to have good and/or bad consequences for the person concerned and/or for others.

29 See reference 9: ch 5.

30 Hare RM. The language of morals. Oxford: Oxford University Press, 1952

31 Hare RM. Descriptivism. Proceedings of the British Academ 1963; 9:115-34. Reprinted in Hare RM. Essays on the moral concepts. London: The Macmillan Press, 1972.

32 See reference 8: 20 .

33 See reference 9: ch 6.
34 See reference 9: chs 6 and 7

35 I do not, by the way, as Boorse suggests, argue that "kidney" is either a "value-laden term" (see reference 32) or "normative" (see reference 56). I argue rather that our ability to speak of kidneys as functional objects (and hence as functioning well or badly) depends on there being an evaluative element, albeit a deeply hidden evaluative element, in its meaning. I have suggested the term "evaluationist" to distinguish this position. See my: Teleology without tears: naturalism, neo-naturalism and evaluationism in the analysis of function statements in biology (and a bet on the twenty-first century). Philosophy, Psychiatry \& Psychology 2000; 7,1:77-94.

36 See reference 8: 104, note 11 .

37 Thornton T. Mental illness and reductionism: can functions be naturalized? Philosophy, Psychiatry \& Psychology 2000; 7,1:6776.

38 Thornton, in reference 37, argues that modern work in the philosophy of mind on the "expanded space of reasons" raises the possibility of a teleological yet value-free account of function. I respond to this important suggestion in part 2 of my Teleology without tears (reference 35 ).

39 See reference 2: 57.

40 Though my example would work equally well for the neural and other mechanisms (ie the part functions) subserving racing car driving.

41 The fact that goals can be described, by the way, no more shows that "goal" is value free, than the fact that morals can be described shows that morality is value-free (see also the start of section 2 of this paper, on describing values). For a more detailed treatment of these issues, see reference 35 : Teleology without tears.

42 The "language" in question includes Boorse's slips from valuefree definition to value-laden use, as above. Similar slips are
pervasive in Jerome Wakefield's analysis of dysfunction (the pervasive in Jerome Wakefield's analysis of dysfunction (the
putatively value-free element in his analysis of disorder as "hutatively value-free element in his analysis of disorder as "harmful dysfunction"- - see reference 35: part 3 of my Teleology without tears. Even Tim Thornton's ingenious use (in refvalue-free (but still teleological) definition of "function" (though not of "dysfunction") relies on value-laden terms such as "saliency" and "natural"; see reference 35: part 2 of my Teleology without tears.

43 See reference 5: 375

44 See reference 8: 61 .

45 Garety PA, Freeman D. Cognitive approaches to delusions: a critical review of theories and evidence. British fournal of Clinical Psychology 1999;38:113-54. It is one of the remarkable feacal Psychology 1999;38:113-54. It is one of the remarkable feabeing paradigmatic symptoms of mental disorder, they have being paradigmatic symptoms of mental disorder, they have of rationality (logic, probability, statistics)" to which Boorse of rationality (logic, prob

46 See reference 9: ch 10.

47 Lewis A. Health as a social concept. British fournal of Sociology 1953;4:109-24

48 Szasz TS. Schizophrenia: the sacred symbol of psychiatry. New York: Basic Books, 1976 .

49 Megone C. Aristotle's function argument and the concept of mental illness. Philosophy, Psychiatry \& Psychology 1998;5,3 187-202.

50 See reference 9: chs $7-10$.

51 Szasz TS. The myth of mental illness. American Psychologist 1960;15:113-118.

52 Szasz TS. Insanity: the idea and its consequences. Chichester: John Wiley and Sons, 1987.

54 Bringing mental disorder back to centre stage is fruitful practically as well as theoretically. For review, see Fulford KWM. Philosophy into practice: the case for ordinary language philosophy. In: Nordenfelt L. Health, science and ordinary language. Amsterdam: Rodopi: ch 2 (forthcoming). Note also that in the final section of A plea for excuses, reference 21, which was written in the $1950 \mathrm{~s}$, Austin, anticipating the modern development of philosophy of psychiatry, pointed to abnormal psychology as a potentially rich resource for linguistic-analytic philosophy.

55 See reference 21: 23.

56 See reference 8: 58 .

57 See reference 8: 99. 